\title{
TEORIA SOCIAL CRÍTICA: PRÁXIS E POLÊMICAS
}

\section{CRITICAL SOCIAL THEORY: PRAXIS AND POLEMICS}

\section{Nilsen Aparecida Vieira Marcondes ${ }^{1}$ Maria Fátima de Melo Toledo²}

Resumo: O pensamento marxista e a explicação marxista de mundo se materializam na Teoria Social Crítica, a qual possui como foco o homem em sua condição de classe. Intenciona-se, neste artigo, partindo do ponto de vista deste referencial teórico crítico, refletir sobre práxis, bem como sobre as polêmicas que emergem quando o assunto é Teoria Social Crítica. Para elaboração deste estudo de natureza qualitativa e exploratória, a abordagem se configurou como bibliográfica. Os resultados apontam que essa Teoria se encontra em contínua evolução, contemplando conceitos e interpretações que, no decorrer da construção de seu processo histórico, não esteve isenta de polêmicas e críticas por parte de alguns estudiosos. Conclui-se, portanto, que essa Teoria, fundamentada no pensamento marxista, não se apresenta como um referencial teórico pronto e acabado porque os acontecimentos históricos são dialéticos e temporais. Palavras-chave: Teoria Social Crítica; Marx; práxis; polêmicas.

Abstract: Marxist thought and Marxist explanation of the world materialize in Critical Social Theory, which has focused on man in his class condition. The intention in this article is the point of view of theoretical critical reflection on practice, as well as the controversies that emerge when it comes to Critical Social Theory. For preparation of this qualitative study and exploratory approach, a bibliography was configured. The results show that this theory is continuously evolving, contemplating concepts and interpretations, which during the construction of its historical process have not been free of controversy and criticism from some scholars. Therefore, this theory, grounded in Marxist thought, is not presented as a theoretical reference point and finished because historical events are dialectic and temporal.

Keywords: Critical Social Theory; Marx; praxis; polemics.

\footnotetext{
1 Mestre em Desenvolvimento Humano: Formação, Políticas e Práticas Sociais - Universidade de Taubaté - Unitau. Assistente Social da Prefeitura Municipal de São José dos Campos/SP. E-mail: nilsenmarcondes@gmail.com.

${ }^{2}$ Doutora em História - Universidade de São Paulo - USP. Docente da Unitau. E-mail: melotoledo@gmail.com.
} 


\section{INTRODUÇÃO}

O pensamento marxista e a explicação marxista de mundo se materializam na Teoria Social Crítica, a qual possui como foco o homem em sua condição de classe. Discutir temáticas referentes a qualquer teoria, que se proponha a respaldar Ciências Sociais, não é tarefa fácil, justamente porque aquilo que se pretende investigar se configura como objeto, mas também sujeito, qual seja, o próprio homem. Intenciona-se, portanto, com este artigo analisar o pensamento de Marx materializado na Teoria Social Crítica. Esta pesquisa se apresenta, quanto à forma de abordagem da temática, como qualitativa, do ponto de vista de seus objetivos, como exploratória e, com relação aos procedimentos técnicos, como bibliográfica. As análises apresentadas apontam que essa Teoria se encontra em contínua evolução, contemplando conceitos e interpretações que, no decorrer da construção de seu processo histórico, não esteve isenta de polêmicas e críticas por parte de alguns estudiosos.

Ao se afirmar que o pensamento marxista e a explicação marxista de mundo se materializam na Teoria Social Crítica, é preciso, anteriormente, reconhecer que o processo de conhecimento é fruto da elaboração mental, mas também da vivência do homem. O homem teoriza em cima de sua vivência, sendo o conhecimento próprio da vida humana, pois o homem tem a consciência que lhe dá a capacidade de visualizar a realidade no plano das ideias. A consciência se apropria da realidade trabalhando com ela em nível intelectual. E a teoria é calcada nessa semente que é o processo cognitivo, produzindo, assim, novos conhecimentos. Pode-se dizer, então, que os principais elementos do conhecimento são o concreto e o abstrato.

A teoria é necessária e nos ajuda muito, mas por si só não fornece os critérios suficientes para estarmos seguros de agir com acerto. Nenhuma teoria pode ser tão boa a ponto de nos evitar erros ela depende da prática - especialmente da prática social - para verificar o maior ou menor acerto do nosso trabalho com os conceitos (KONDER, 1981b, p. 164, grifo do autor).

Portanto, teoria e prática são igualmente necessárias, no processo de construção do conhecimento intelectual, à medida que o homem somente acumula tais conhecimentos por meio das experiências e da realidade que vê. Sem a realidade, o homem não é capaz de produzir conhecimentos e, portanto, não será capaz de avançar do senso comum, podendo cair na simplificação demasiada da realidade o que, por sua vez, leva a uma inocência teórica (BARREIRA, 1992).

Segundo Pereira (1990, p. 70): "A teoria que não se enraíza não é teoria porque permanece no horizonte da abstração porque não ascendeu ao nível da ação." E ainda: "Toda vez que uma teoria tenta estabelecer-se fora do horizonte da prática, ela vira pura abstração." (PEREIRA, 1990, p. 76). E é justamente para não incorrer a esse risco que Marx, Engels e Lênin (s/d apud KONDER, 1981b, p. 179) defendiam que: "A prática exige um reexame da teoria e a teoria serve para criticar a prática em profundidade, serve para questionar e corrigir a prática."

Portanto, pensar a teoria como "fruto de uma temporalidade histórica" (BARREIRA, 1992, p. 82), imprimi-lhe uma característica de flexibilidade enquanto recurso que se usa para entender o mundo, uma lente por meio da qual se olha para interpretar e compreender a realidade. 
Para Santos (1999, p. 215), é defensável pensar teoria como "[...] a consciência cartográfica do caminho que vai sendo percorrido pelas lutas políticas, sociais e culturais que ela influencia tanto quanto é influenciada por elas". Isso remete para o entendimento de que teoria é, portanto, influenciada por aspectos ideológicos que, direta ou indiretamente, marcam o pensamento e a ação de todos os homens (PEREIRA, 1990).

Por fim, diante do que foi exposto como Teoria no âmbito geral, reconhece-se agora, que em se tratando de Teoria Social Crítica concorda-se com Santos (1999, p. 197) quando afirma que:

Teoria crítica é toda teoria que não reduz a realidade ao que existe. A realidade é considerada pela teoria crítica como um campo de possibilidades. A análise crítica assenta-se no pressuposto de que a existência não esgota as possibilidades da existência e que, portanto, há alternativas susceptíveis de se superar. O desconforto, o inconformismo ou a indignação suscitam impulso para teorizar a sua superação.

Gouvêa (1991), tendo também como foco a Teoria Social Crítica, coloca que em Marx é perceptível a presença de aspectos relacionados ao progresso, aliás, segundo a autora,

Foi no paradigma marxista que a secularização da ideia de progresso teve seu apogeu. É nítida em sua Teoria a premissa de um progresso inevitável e irreversível onde barbárie, escravidão, feudalismo, capitalismo consistem em etapas necessárias ao progresso da história humana, ele [Marx] com propriedade discute ideias de aparência e essência, parte e todo, singular, universal, presente e passado, lógico e histórico (GOUVÊA, 1991, pp. 150-151).

A Teoria Social Crítica foi gestada dentro de um contexto Capitalista. E, nesse Sistema Econômico, Marx considera que o homem é submetido a um quadro de alienação, restando-lhe como alternativa assumir uma postura crítica frente a essas realidades que o oprime, sendo que a práxis é justamente aquela que "[...] permite a suspensão dessa alienação evidentemente não sem contradições e conflitos" (BARROCO, 2007, p. 194).

No âmbito das Ciências Sociais, não obstante relevância da Teoria Social Crítica no respaldar o ensino, a pesquisa e a extensão, verifica-se que, por se encontrar em contínua evolução, contemplando conceitos e interpretações no decorrer da construção de seu processo histórico, não esteve isenta de polêmicas e críticas por parte de alguns estudiosos.

\section{DESENVOLVIMENTO}

\subsection{Práxis enquanto elemento indissociável da Teoria Social Crítica}

Como alguns setores da sociedade impedem a participação ativa do homem no âmbito societário, a crítica traduzida numa ação política transformadora e consciente, ou seja, numa práxis, deveria ser a resposta do homem (PAULA, 1992). E isso porque a práxis, segundo Sarmento (2011, p. 211): "[...] é entendida não como mera atividade da consciência, mas sim como atividade material do homem social, que reconhece e pretende não apenas a interpretação de si e do mundo, mas também sua transformação". 
Setubal (2007, p. 71) enfatiza que: "A práxis não pode ser confundida com trabalho porque na dialética histórica embora toda práxis seja trabalho, nem todo trabalho se constitui práxis." Esta afirmação faz eco às palavras de Paulo Netto e Braz (2011, pp. 53-54) quando colocam que:

O ser social é mais que trabalho, ele cria também objetivações que transcendem o universo do trabalho e a categoria teórica que explica esta realidade é a práxis. A práxis envolve o trabalho, mas inclui muito mais que ele: inclui todas as objetivações humanas, revela o homem como ser criativo e autoprodutivo. $O$ homem é produto e criação da sua autoatividade, ele é o que (se) fez e (se) faz (PAULO NETTO; BRAZ, 2011, pp. 53-54, grifos dos autores).

Sarmento (2011, p. 211) sustenta que: "Está implícito ao homem, em sua sociabilidade e historicidade, um exercício permanente de ação e reflexão, uma práxis que vai além da interpretação das coisas e do mundo, é intenção e ação voltadas à transformação". É conveniente ainda reforçar que:

'Práxis' significa ação aliada à reflexão. Quando alguém só se envolve em reflexões e debates, temos o verbalismo: fala, mas nada faz. Quando uma pessoa só fica agitando e agitando-se sem pensar o porquê, temos o ativismo. A filosofia da práxis dá valor aos dois lados da questão. Marx sempre se opôs à divisão entre trabalho intelectual e trabalho manual. Marx distinguia dois aspectos inseparáveis na práxis. A dimensão produtiva [que] se refere ao trabalho na fábrica, no escritório: trata-se da produção material da existência e a dimensão social que é política e se verifica em toda a práxis, mas exige um grau de consciência (GADOTTI, 1991, pp. 66-67, grifos do autor).

Portanto, na perspectiva dialética de Marx: "Práxis não deve ser traduzida como prática apenas, porque é mais do que prática. Práxis é uma concepção de mundo, é uma forma de olhar o mundo, de intervir no mundo" (PAULA, 1992, p. 34).

A práxis sempre foi elemento já integrante e pedra angular da atividade filosófica e política de Karl Marx e Friedrich Engels. Ambos já haviam considerado imprescindível juntar suas críticas teóricas à sociedade capitalista com um movimento político-prático que visasse à transformação concreta dessa sociedade (SOUZA; SECCO, 2009, p. 66).

Considera-se que:

A práxis não tem como objeto somente a matéria; porque também supõe formas de interação cultural entre os homens. A práxis interativa, por exemplo, emerge como necessidade posta pelo desenvolvimento da sociabilidade, nesse sentido a vida social se constitui a partir de várias formas de práxis. (BARROCO, 2007, p. 30).

Portanto: "A luta por objetivos emancipatórios é intrínseca à Teoria Crítica" (SANTOS, 1999, p. 199). Logo, cabe ao pesquisador interessado em respaldar-se na Teoria Social Crítica, procurar "[...] problematizar a realidade, mesmo que ela se apresente como 'natural', 'evidente' " (GADOTTI, 1991, p. 49, grifos do autor). 


\subsection{Considerações polêmicas a cerca da Teoria Social Crítica}

Diversos autores, citados a seguir, sustentam e realizam reconstruções sofisticadas e originais a respeito do pensamento de Marx, entretanto, cada um deles, a sua maneira e em distintos graus, procuram expressar realidades conceituais que consideram dignas de revisão ou mesmo nova interpretação por acreditarem que toda e qualquer Teoria, enquanto ação humana, é suscetível de evoluções, adequações e desenvolvimento.

Portanto, a opção pelo respaldo teórico marxista não suprime a compreensão de que tal Teoria não se apresenta como uma verdade incontestável, válida para qualquer período temporal e para todos os contextos. O próprio Marx (1843 apud ARON, 2008, p. 234) afirmava que: "O homem constrói seu futuro pela ação, o futuro é imprevisível em detalhes".

Segundo Paula (1992, pp. 20-21): "Não é verdade que o marxismo tenha uma validade geral e que os princípios, dos quais o marxismo parte sejam universais, no sentido de ahistóricos, no sentido de atemporais". E, para reforçar isso, Carvalho (1992, pp. 63-64) coloca que:

O Marxismo não pode ser visto como princípio e fim de tudo, o que veementemente coloca a exigência do diálogo com outras Teorias. É a necessidade da articulação entre paradigmas teóricos como condição da Ciência dar conta de explicar as múltiplas dimensões dos fenômenos sociais neste final de século.

Para Aron (2008, p. 532), a interpretação científica respaldada pela Teoria Social Crítica "[...] sempre gerou controvérsias, sobretudo a cada vez que se tornava necessário adaptá-la aos acontecimentos novos ou a um aspecto novo da história do capitalismo". E tais controvérsias são mesmo de se esperar com naturalidade porque: "A situação histórica atual é, evidentemente, muito distinta da situação sobre a qual refletiu Marx" (ARON, 2008, p. 560).

Existe, por parte de um diversificado e heterogêneo grupo de estudiosos, uma postura de oposição frente à Teoria Social Crítica. E não parece que faltem considerações que suscitem indignação ou até mesmo desconforto quando o assunto é concentrado nos eixos temáticos marxistas e isso desde a época em que Marx ainda era vivo.

O filósofo Pierre-Joseph Proudhon, contemporâneo de Marx, discordava do filósofo e entre ambos existiam embates teóricos ferozes que se manifestavam por meio da elaboração de livros: Proudhon escreveu Filosofia da Miséria como forma de criticar a postura teórica de Marx, e este respondeu às críticas com o livro Miséria da Filosofia. Não obstante, apesar das discordâncias teóricas, existia respeito pessoal entre os autores. É interessante observar o tipo de arma utilizada nos embates teóricos entre ambos: redação de livros. E, ainda, na resposta, Marx tem o cuidado de utilizar as mesmas palavras do título do livro de Proudhon, valorizando sua postura teórica, mas invertendo a ordem das palavras (ARON, 2008; GADOTTI, 1991; KONDER, 1981a).

A centralidade das críticas de Proudhon se baseava no fato de que ele,

[...] não aprovava a revolução como meio de transformar a estrutura econômica e social, pois ela traria prejuízo aos trabalhadores, desarmonizaria o sistema de produção e faria cair o fluxo de mercadorias ele propunha uma nova ordem social, baseada na pequena propriedade, na concessão de créditos gratuitos e sem a existência de um poder central. E ainda se opunha à greve, que considerava um 
crime contra o sistema econômico (GADOTTI, 1991, p. 83).

Outro conterrâneo do período histórico de Marx foi Mikhail Bakunin que o considerava muito prepotente e autoritário. A discordância entre ambos se pautava na concepção diferenciada que possuíam sobre o socialismo, na grande defesa da greve geral proposta por Bakunin (que aos olhos de Marx era um mito), e no direito à herança que Bakunin queria abolir e Marx não, por entender que a questão da herança era consequência da propriedade privada, mas não o problema em si. Mas, apesar de tudo, Bakunin admirava o profundo conhecimento e a forma com que Marx contemplava a história (GADOTTI, 1991; KONDER, 1981a).

Ferdinand Lassalle, líder carismático de movimentos operários, advogado e escritor, mantinha embates teóricos com Marx. A motivação situava-se na "forma como deveria ser realizada a unificação dos estados germânicos independentes" e quanto ao fato do "Partido Operário Alemão esperar ajuda do Estado burguês na implantação de uma educação democrática e popular e na criação de cooperativas", realidade defendida por Lassalle e abominada por Marx (SOUZA; SECCO, 2009, p. 55). Apesar de muitas divergências entre os dois, houve um momento em que os partidos que se vinculavam a Marx e a Lassalle se uniram e concordaram em realizar uma ação política comum (GADOTTI, 1991; KONDER, 1981a).

Muitas outras críticas contra a Teoria Social de Marx e Engels existiram, inclusive dos próprios sindicalistas da Inglaterra que nunca perdoaram o fato de Engels, melhor amigo de Marx e companheiro de ideal, ser um industriário. Engels, mesmo a contragosto de fato, era mesmo um industriário. Seu pai era sócio de uma empresa em Londres e as dificuldades financeiras pelas quais a família de Marx passava era tamanha, que Engels se viu praticamente obrigado a retomar seu trabalho na empresa do pai, como forma de auxiliar com seu salário a manutenção da família de Marx, cujas filhas o consideravam, também, como um pai (GADOTTI, 1991).

Agora, parafraseando alguns autores, como Barreira (1992), Carvalho (1992), Gadotti (1991) e Santos (1999), todos assentes em estudos que argumentam sobre as limitações existentes no universo teórico de Marx, tem-se que a Teoria Social Crítica pode comprometer-se com análises generalizantes, globalizantes, totalizantes que impedem apreensão dos comportamentos concretos, dos novos atores sociais, da forma como pensam sobre determinada realidade e como percebem as contradições culturais, bem como de suas novas formas peculiares de luta.

Segundo esses autores, esse comprometimento da Teoria Social Crítica poderia restringir a explicação da dinâmica do real e deixar de lado dimensões importantes da realidade. E, ainda, sustentam também a presença do determinismo em algumas correntes marxistas, o que leva os atores sociais a transformar-se "em objeto e os comportamentos em ações automatizadas", conforme expressa Carvalho (1992, p. 48). Portanto, nessa linha de pensamento: "O Marxismo é viável, na medida em que ele se abre e estabelece um efetivo diálogo com outras perspectivas" (CARVALHO, 1992, p. 65).

A citação que segue é de Santos (1999, p. 202), sendo que o foco da crítica incide sobre universalismos ou totalidades, que, segundo ele, são defendidos pela Teoria Social Crítica:

Não há um princípio único de transformação social. Não há agentes históricos Revista Univap - revista.univap.br únicos, nem uma forma única de dominação. São múltiplas as formas de 
dominação. São múltiplas as faces da dominação e da opressão e muitas delas foram negligenciadas pela teoria crítica moderna. Sendo múltiplas as faces da dominação, são múltiplas as resistências e os agentes que as protagonizam.

Para Rouanet (s/d apud CARVALHO, 1992, p. 60), para além da questão cognitiva, é importante também que seja focada a realidade "[...] dos valores, das paixões, dos sentimentos, rompendo a prisão do trabalho exclusivo com o mundo dos fatos". O próprio Rouanet denomina sua Teoria de Razão Sábia, ou seja, aquela que possibilita ao pesquisador ser capaz de atuar também com "[...] a subjetividade, procurando trabalhar inclusive, até questões do inconsciente, que estão presentes nos atos racionais" (ROUANET, s/d apud CARVALHO, 1992, p. 60).

A autora Barreira (1992) enfatiza o surgimento de uma nova realidade, considerada importante dentro da sociedade brasileira, e que deveria ser contemplada pela Teoria Social Crítica de forma mais acentuada. Trata-se do surgimento dos movimentos sociais, onde, dentro deles, começa a ganhar destaque a fala dos sujeitos.

Segundo ela,

As expressões da realidade social não necessariamente passam só por aquela dimensão clássica das noções de classe setores tidos como silenciosos e marginais da sociedade de repente passaram a se organizar. Com isso, uma situação que parecia inteiramente descabida para as amplas reflexões, passou a ter lugar certos setores passaram a se expressar e compreendeu-se que o sujeito também tinha o seu processo de construção e de compreensão da realidade (BARREIRA, 1992, pp. 75-76).

Habermas (s/d apud GADOTTI, 1991, p. 92) critica em Marx:

[...] uma demasiada confiança no progresso e na ciência. Ele mostra a necessidade de se criarem espaços de sociabilidade que superem a racionalização técnica, que desumaniza as pessoas. Para Habermas, a técnica e a ciência tornaram-se instrumentos do capitalismo para impor às massas a ilusão de que a dominação que sofrem é legítima.

De acordo com Carvalho (1992, p. 54), a oposição pós-moderna assume uma postura de rejeição frente às grandes teorias que foram plasmadas no período da modernidade, e isso "[...] em nome de uma Ciência Operacional que privilegia o critério tecnológico onde tudo possa se transformar em bits de informação". Por outro lado, essa rejeição possibilitou que emergisse "[...] uma tendência no interior das Ciências Sociais que hoje reivindica que se trabalhe o micro, o pontual, o particular, o que exige a utilização de novas abordagens analíticas" (CARVALHO, 1992, p. 55).

As dificuldades em construir hoje uma teoria crítica podem formular-se devido promessas da modernidade não terem sido cumpridas, transformando-se em problemas para os quais parece não haver solução a disjunção entre a modernidade dos problemas e a pós-modernidade das possíveis soluções deve ser assumida e transformada num ponto de partida para enfrentar os desafios da construção de uma teoria crítica pós-moderna. (SANTOS, 1999, p. 204).

Foucault (s/d apud BARREIRA, 1992) também fornece subsídios à temática das limitações da 
Teoria Social Crítica. Para ele, tal Teoria deveria ter explorado mais alguns elementos na dinâmica e na interpretação social, como, por exemplo:

Análises referentes ao microcotidiano onde a dominação social e o poder perpassam outros mecanismos nem sempre visíveis onde também o poder está no modo de olhar, de sentar, de falar e que seria preciso incorporar estas especificidades, ou essas outras formas visíveis de dominação social, no estudo da realidade (FOCAULT, s/d apud BARREIRA, 1992, p. 76).

Acresce, também, o fato de Marx ser considerado como um teórico fatorialista, tido como analista da história e da sociedade focado somente no "[...] 'fator econômico' como determinante em relação aos 'fatores' sociais, culturais etc." (BARREIRA, 1992, p. 13, grifos da autora). Quanto a isso, Konder (1981b, p. 177) esclarece que:

Nas duas primeiras décadas do século XX, difundiu-se entre os socialistas a ideia falsa - de que, segundo Marx, os 'fatores econômicos' provocavam de maneira mais ou menos automática, a evolução da sociedade (sem que os homens - sujeitos do efetivo movimento da história - tivessem um espaço significativo para tomarem suas iniciativas). Essa concepção era oportunista para criar a ideia de que: quem não enxerga nada que dependa da sua ação tende facilmente a instalar-se na passividade (tende a contemplar a história, em vez que fazê-la) (KONDER, 1981b, p. 177 , grifos do autor).

Lukács (s/d apud KONDER, 1981b, p. 178) advertiu que: "Não é a predominância dos motivos econômicos na explicação da história que distingue o marxismo: é o ponto de vista da totalidade." Nessa mesma direção, Paulo Netto (2011, p. 14) reforça a argumentação colocando que,

[...] também Engels, em carta de setembro de 1890, já advertira contra essa deformação: recordando que Marx e ele sustentavam tão somente a tese segundo a qual a produção e a reprodução da vida real apenas em última instância determinavam a história. Tal concepção reducionista, que nada tem a ver com o pensamento de Marx, é compartilhada também por muitos dos seus adversários teóricos. Weber, por exemplo, criticou, na 'concepção materialista da história', as explicações 'monocausalistas' dos processos sociais, isto é, explicações que pretendiam esclarecer tudo a partir de uma única causa (ou 'fator'); a crítica é procedente se relacionada à teoria efetivamente 'monocausalistas', mas é inteiramente inepta se referida a Marx, uma vez que, como realçou um de seus mais qualificados estudiosos, Lukács 'é o ponto de vista da totalidade e não a predominância das causas econômicas na explicação da história que distingue de forma decisiva o marxismo da ciência burguesa' " (PAULO NETTO, 2011, p. 14, grifos do autor).

Engels (2010 apud PAULO NETTO, 2011, p. 14) diz: "Nem Marx, nem eu jamais afirmamos mais que isto. Se alguém o tergiversa, fazendo do fator econômico o único determinante, converte esta tese numa frase vazia, abstrata, absurda".

A Teoria Social Crítica nos seus primórdios, desde Marx e Engels, nunca pretendeu ser normativa, mas sim constatativa. Ambos precursores sempre reconheceram que: 
Nas condições de insuficiente desenvolvimento das forças produtivas humanas e de divisão da sociedade em classes, a economia tem imposto, em última análise, opções estreitas aos homens que fazem a história. Isso não significa que a economia seja o sujeito da história, que a economia vá dominar eternamente os movimentos do sujeito humano. Ao contrário: a dialética aponta na direção de uma libertação mais efetiva do ser humano em relação ao cerceamento de condições econômicas ainda desumanas (KONDER, 1981b, p. 178-179, grifos nossos).

Em suas análises, Paulo Netto (2011, p. 15) coloca que as maiores críticas da atualidade direcionadas à Teoria Social dizem respeito à "[...] suposta irrelevância das dimensões culturais e simbólicas, com todas as consequências daí derivadas para sua perspectiva metodológica". Nesse aspecto, esse autor contra argumenta a crítica informando que Marx considerava como de extrema relevância os aspectos relacionados as tradições. Prova disso se verifica quando "tangencia a propriedade comunal entre os eslavos" e quando assume "permanentes preocupações com a especificidade de esferas ideais como a arte" (PAULO NETTO, 2011, p. 15).

Ainda, em se tratando de contra argumentação às críticas da atualidade, tem-se que:

O pretenso 'determinismo' imerso na teoria social de Marx estaria deixando-a comprometida com uma teleologia evolucionista - ou seja, para Marx, uma dinâmica qualquer (econômica, tecnológica etc.) dirigiria necessária e compulsoriamente a história para um fim de antemão previsto (o socialismo). Vários estudiosos já mostraram sobejamente a inconsistência dessa crítica. Praticamente todas essas interpretações equivocadas podem ser superadas com o recurso a fontes que operam uma análise rigorosa e qualificada da obra marxiana. Entretanto, é a recorrência aos próprios textos de Marx que propicia o material indispensável e adequado para o conhecimento do método que ele descobriu para o estudo da sociedade burguesa (PAULO NETTO, 2011, p. 16, grifos do autor).

Continuando na perspectiva da análise comparativa entre os diversos autores que colocam seus pontos de vista a respeito da Teoria Social, verifica-se, também, estudiosos que fazem a seguinte afirmação: "A 'Teoria' iniciada por Karl Marx e ainda em desenvolvimento pode ser estudada em seu âmago, mas sua força social precisa ser lida em outra temporalidade" (SOUZA; SECCO, 2009, p. 35, grifo dos autores).

\subsection{A Teoria Social Crítica e sua presença histórica atual}

Não obstante apontamentos reflexivos dos diversos autores supracitados acredita-se que a Teoria Social Crítica, por seu turno, apresenta-se como um importante instrumento que respalda a investigação científica na área de ciências sociais aplicadas, quando se deseja refletir sobre o contexto societário, enquanto um emaranhado de relações dinâmicas e relacionadas entre si. Além disso, segundo Behring (2008, pp. 31-32): "A Teoria Social Crítica contém os mais ricos recursos heurísticos, categorias teóricas e aportes para um mergulho analítico nos processos sócio-históricos da sociedade burguesa e seus movimentos contínuos de transformação" (BEHRING, 2008, pp. 3132).

Gadotti (1991, p. 9), ao tratar da importância, validação e legitimidade da Teoria Social Crítica 
no contexto investigativo, faz a seguinte comparação: "Costuma-se dizer que, sob certos aspectos, a vida em sociedade se assemelha a um campo minado, que só pode ser atravessado com segurança com a ajuda de um instrumento que detecte as bombas enterradas". Diante disso, Souza e Secco (2009, p. 7) destacam que: "As contribuições do pensamento marxista permanecem não apenas acurado, como cada vez mais atual".

Konder (1981a) acrescenta novos elementos à reflexão, ao afirmar que a Teoria Social Crítica foca sua lente interpretativa da realidade na explicação das transformações e apresenta-se como um desafio intelectual, pois defende a importância de se investigar a raiz daquela realidade que se coloca ao pesquisador e à necessidade de contextualizá-la no âmbito macro da sociedade, pois somente assim o conhecimento construído adquire relevância científica. Isso significa que as investigações devem buscar as mais completas e seguras informações que se possam obter a respeito do objeto de pesquisa.

Pautando-se na Teoria Social Crítica, ao se buscar o conhecimento sobre determinado objeto, realidade ou sujeito, tem-se clareza de que encerram em si muito mais complexidade e riqueza de informações do que aquilo que se pode apreender pela via do conhecimento (PONTES, 1989). Isso porque: "As aparências das coisas nem sempre correspondem à sua realidade" (BORCHARDT, 1982, p. 194).

A investigação respaldada por esse referencial analítico considera o homem como sujeito de sua própria história, enfatizando que a realidade social é transformável porque construída pelos próprios homens, podendo, portanto, ser mudada também por eles, por meio da práxis entendida como ação projetada, refletida, consciente e transformadora. A Teoria Social possui duas características essenciais: a crítica e a autocrítica. Essas características contribuem para que o método dialético estimule o pesquisador a rever o passado à luz do que se apresenta no momento presente, indagando esse presente em nome das realidades futuras (KONDER, 1981b).

A reconstrução da realidade investigada, a partir da visão marxiana, possibilita desvendar situações que emergem do movimento. A noção de conjuntura, bem como o conceito de contradição, deve acompanhar o pesquisador que se norteia pela Teoria Social Crítica, pois representam aspectos importantes a serem analisados dentro de um contexto não estático, não subordinado à lei de causa e efeito. Como contributo nessa direção, Aron (2008, p. 441) afirma que: "O método de pesquisa que se respalda em Marx, consiste em ir do abstrato ao concreto, quer dizer, das categorias ao conjunto histórico singular das categorias abstratas para progressivamente reencontrar a totalidade concreta" (ARON, 2008, p. 441).

\section{CONCLUSÃO}

Ao se tratar de teoria, conclui-se, portanto, que é preciso considerar que o homem não pensa, não projeta e não age no vazio absoluto, por isso todo e qualquer conhecimento, por mais estruturado e complexo que se apresente no plano intelectual, parte sempre do ponto inicial, em outras palavras do conhecimento sensível. Por conseguinte: "A teoria não se trata do ato intelectual em si só, isoladamente, mas da ação do homem como um todo, envolvido no mundo e na relação 
com o outro" (PEREIRA, 1990, p. 13).

O fato de que a construção do conhecimento parte do concreto reforça a importância da ação do homem. Nesse processo, o homem é o único ser da natureza que se preocupa em buscar um sentido para si mesmo e para o mundo ao seu redor. Logo, mais que consequência do ato intelectual, teoria é também resultado da ação humana, única capaz de gerar cultura. A ação animal, por exemplo, enquanto prática pura em si não é capaz de gerar cultura (PEREIRA, 1990).

Quanto à Teoria Social Crítica, reconhece-se que vem trazer contributos à medida que leva o pesquisador a compreender que: "A filosofia marxista procura justamente se engajar na prática concreta de construção do ser humano, sendo por isso chamada de 'filosofia da práxis' por Antonio Gramsci" (GADOTTI, 1991, p. 66, grifo do autor).

Em se tratando das polêmicas, como se pode verificar, inúmeros autores citados neste estudo expressaram, convictamente, em suas respectivas obras, seus pensamentos acerca dessa Teoria, pontuando e fazendo considerações que pudessem contribuir com o desenvolvimento do conhecimento a respeito.

Isso posto, considera-se que essa Teoria, fundamentada no pensamento marxista, não se apresenta como "[...] uma receita de ideias prontas que devem ser aplicadas a situações diversas [...]" (GADOTTI, 1991, p. 62) porque, "na história tudo é temporal" (SETUBAL, 1991, p. 119) e como se sabe: "Cada estilo de pensamento ou cada método científico surge numa determinada configuração histórica” (GOUVÊA, 1991, p. 151).

Compreende-se, então, que: "Não há uma única teoria capaz de dar conta da explicação da realidade, mas múltiplas teorias em constantes interlocuções críticas entre si” (FAUSTO NETO, 1992, p. 103). E, ainda, que: "Não se pode permanecer no vício dogmático desta ou daquela abordagem entendidas como conflitantes [...]" (PEREIRA, 1990, p. 29), porque: "Na ciência se está sempre dando um passo a partir de onde o outro parou" (PEREIRA, 1990, p. 45).

Portanto, quando se faz a opção pela Teoria Social Crítica, no sentido de trilhar pelos caminhos da busca do conhecimento e responder às indagações que se apresentam ao pesquisador, é preciso reconhecer que as realidades sociais se configuram processos abertos e transitórios. Nesse sentido, torna-se indispensável aos profissionais que se propõem a estudar os aspectos que envolvem a vida em sociedade voltar seu olhar crítico e analítico para a compreensão do contexto enquanto contínuo movimento.

\section{REFERÊNCIAS}

ARON, R. O Marxismo de Marx. Tradução por Jorge Bastos. São Paulo: Arx, 2008.

BARREIRA, I. A Pesquisa no Debate Contemporâneo e o Serviço Social. Cadernos ABESSCEDEPSS, n. 5, pp. 70-83, maio 1992.

BARROCO, M. L. S. Ética e Serviço Social: fundamentos ontológicos. São Paulo: Cortez, 2007.

BEHRING, E. R. Brasil em contrarreforma: desestruturação do Estado e a perda de direitos. 2. ed. São Paulo: Cortez, 2008. 
BORCHARDT, J. Karl Marx O Capital. 7. ed. Rio de Janeiro: Guanabara, 1982.

CARVAlHO, A. M. P. de A Pesquisa no Debate Contemporâneo e o Serviço Social. Cadernos ABESS-CEDEPSS, n. 5, pp. 43-66, maio 1992.

FAUSTO NETO, A. M. Q. "Taller" de investigação e projetos sociais. Cadernos ABESS-CEDEPSS, n. 5, pp. 96-107, maio 1992.

GADOTTI, M. Marx: Transformar o Mundo. São Paulo: FTD, 1991.

GOUVÊA, G. F. P. A ideia de progresso e a explicação nas Ciências Sociais. Revista Serviço Social \& Sociedade, São Paulo, v. 12, n. 35, pp. 134-153, 1991.

KONDER, L. A. M. C. Marx: Vida e Obra. Rio de Janeiro: Paz e Terra, 1981a.

O que é Dialética. v. 6. São Paulo: Brasiliense, 1981b, p.137-192.

PAULA, J. A. A produção do conhecimento em Marx. In: Cadernos ABESS-CEDEPSS, n. 5, pp. 17-42, maio 1992.

PAULO NETTO, J. Introdução ao estudo do método de Marx. São Paulo: Expressão Popular, 2011.

PAULO NETTO, J.; BRAZ, M. Economia Política: uma introdução crítica. São Paulo: Cortez, 2011.

PEREIRA, O. O que é Teoria. São Paulo: Brasiliense, 1990.

PONTES, R. N. A propósito da categoria de mediação. Revista Serviço Social \& Sociedade, São Paulo, v. 10, n. 31, pp. 5-25, 1989.

SANTOS, B. de S. Porque é tão difícil construir uma teoria crítica. Revista Crítica de Ciências

Sociais, $\quad$ n. $54, \quad$ jun. $1999 . \quad$ Disponível em: <http://www.boaventuradesousasantos.pt/media/pdfs/Porque e tao dificil construir teoria critica RCCS54.PDF>. Acesso em: 05 set. 2012.

SARMENTO, H. B. de M. Ética e Serviço Social: fundamentos e contradições. Revista Katálysis, Florianópolis, v. 14, n. 2, pp. 210-221, jul./dez. 2012.

SETUBAL, A. A. Hegel e Marx: duas concepções para entendimento de práxis. Revista Serviço Social \& Sociedade, São Paulo, v. 12, n. 35, pp. 103-133, 1991.

Desafios à pesquisa no Serviço Social: da formação acadêmica à prática profissional. Revista Katálysis, Florianópolis, v. 10, n. especial, pp. 64-72, 2007.

SOUZA, L. E. S. de (Org.); SECCO, L. Marx da Economia à Revolução. São Paulo: LCTE, 2009. 